\section{Commentary: What does the future hold for coronary bypass surgery?}

\author{
Bryon A. Tompkins, MD, and Tomas A. Salerno, MD
}

With the introduction of off-pump coronary bypass surgery by Buffolo and Benetti, ${ }^{1,2}$ a variety of incisions and techniques have evolved, ${ }^{3}$ aimed at decreasing morbidity and mortality while increasing longevity. Median sternotomy and on-pump revascularization continues to be the most widely used technique. Morbidity of postoperative pain, stroke, sternal wound infection, and long-term durability of multivessel bypass remain a concern. A combination of off-pump and minimally invasive approaches that avoid median sternotomy, particularly in the setting bilateral internal thoracic artery (BITA) harvesting, has evolved during the last 20 years. ${ }^{4}$ Davierwala and associates ${ }^{5}$ previously reported their vast experience with complete arterial revascularization with BITA grafts through a median sternotomy. ${ }^{5}$ This proficient off-pump group of surgeons has now gone a step further, and in this issue of the Journal, Davierwala and colleagues ${ }^{6}$ report complete arterial revascularization with BITA grafts both harvested through a single left minithoracotomy with the aid of a subxiphoid sternal lift facilitating the right internal thoracic artery harvesting. The procedure was performed in nonobese men in their mid60 s, with good pulmonary and cardiac function and favorable cardiothoracic ratio $(<50 \%)$. The technique used a Y anastomosis between the right and left internal thoracic arteries, with the assistance of stabilizers and new devices. Graft patency was confirmed by flowmetry. Results were excellent, demonstrating the efficacy and safety of the procedure.

There are key salient points that should be highlighted. First, the use of BITAs has been associated with increased postoperative sternal wound infections; BITA harvesting through a minithoracotomy eliminates this problem and may be the optimal choice for patients with a predicted survival longer than 10 years. $^{7}$ Second, the patient must be able to tolerate single-lung ventilation. Third, obese patients were excluded from this series. It is therefore evident

From the Division of Cardiothoracic Surgery, University of Miami Miller School of Medicine and Jackson Memorial Hospital, Miami, Fla.

Disclosures: Authors have nothing to disclose with regard to commercial support.

Received for publication Jan 6, 2020; revisions received Jan 6, 2020; accepted for publication Jan 6, 2020; available ahead of print Jan 31, 2020.

Address for reprints: Tomas A. Salerno, MD, Division of Cardiothoracic Surgery, University of Miami Miller School of Medicine and Jackson Memorial Hospital, 1611 NW 12th Ave, Miami, FL 33136 (E-mail: tsalerno@med.miami.edu).

J Thorac Cardiovasc Surg 2021;162:1120-1

$0022-5223 / \$ 36.00$

Copyright (c) 2020 by The American Association for Thoracic Surgery

http://dx.doi.org/10.1016/j.jtcvs.2020.01.029

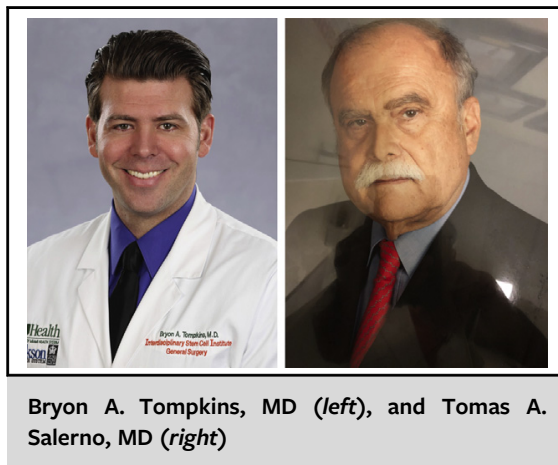

CENTRAL MESSAGE

Surgeons explore their limits in off-pump

minimally invasive myocardial revascu-

larization with total arterial grafting with

both LITA and RITA by left minithora-

cotomy with a subxiphoid sternal lift.

that young patients without cardiomegaly or pulmonary dysfunction are ideal candidates for this procedure. Moreover, there should be no question that minimally invasive incisions are more challenging. Even surgeons familiar with off-pump operation through a median sternotomy face a steep learning curve as a result of operating in a confined space with unfamiliar instruments. Interestingly, Davierwala and colleagues ${ }^{6}$ recommend that surgeons interested in this procedure should begin by performing standard off-pump coronary artery bypass through a median sternotomy, a technique that has been available for more than 30 years.

There is no question that this field is heading in the direction of minimally invasive complete arterial revascularization, as Davierwala and collagues ${ }^{6}$ report here. Because the left internal thoracic artery to left anterior descending coronary artery graft is the major determinant of survival, hybrid revascularization, ${ }^{8}$ which includes lateral vessel stenting, may emerge as another option. ${ }^{9}$ With the emergence of these new techniques, coronary revascularization may become its own subspecialty. As predicted more than 20 years ago, ${ }^{10}$ the next generation of cardiac surgeons will undoubtedly have to become familiar with and develop comfort in performing such procedures, which are likely to be favored by both cardiologists and our patients.

\section{References}

1. Benetti FJ, Naselli G, Wood M, Geffner L. Direct myocardial revascularization without extracorporeal circulation. Experience in 700 patients. Chest. 1991;100:312-6.

2. Buffolo E, Andrade JC, Succi J, Leão LE, Gallucci C. Direct myocardial revascularization without cardiopulmonary bypass. Thorac Cardiovasc Surg. 1985;33:26-9.

3. Reser D, Holubec T, Caliskan E, Guidotti A, Maisano F. Left anterior small thoracotomy for minimally invasive coronary artery bypass grafting. Multimed Man Cardiothorac Surg. 2015;2015. 
4. Calafiore AM, Giammarco GD, Teodori G, Bosco G, D’Annunzio E, Barsotti A, et al. Left anterior descending coronary artery grafting via left anterior small thoracotomy without cardiopulmonary bypass. Ann Thorac Surg. 1996;61: 1658-63; discussion 1664-5.

5. Davierwala PM, Leontyev S, Garbade J, Lehmann S, Holzhey D, Misfeld M, et al. Off-pump coronary artery bypass surgery with bilateral internal thoracic arteries: the Leipzig experience. Ann Cardiothorac Surg. 2018;7:483-91.

6. Davierwala PM, Sgouropoulou S, Hasheminejad E, Von Aspern K, Misfield M, Borger MA. Minimally invasive coronary bypass surgery with bilateral internal thoracic arteries: early outcomes and angiographic patency. J Thorac Cardiovasc Surg. 2021;162:1109-19.e4
7. Lytle BW. Bilateral internal thoracic artery grafting. Ann Cardiothorac Surg. 2013;2:485-92.

8. Gaudino M, Angelini GD, Antoniades C, Bakaeen F, Benedetto U, Calafiore AM, et al; Arterial Grafting International Consortium (ATLANTIC) Alliance. Offpump coronary artery bypass grafting: 30 years of debate. J Am Heart Assoc. 2018;7:e009934.

9. Salerno TA, Ferreira AC. Is conventional coronary artery surgery being replaced by the hybrid approach? J Thorac Cardiovasc Surg. 2016;151: 1702-3

10. Calafiore AM, Angelini GD, Bergsland J, Salerno TA. Minimally invasive coronary artery bypass grafting. Ann Thorac Surg. 1996;62:1545-8.
See Article page 1109.

\section{Commentary: Coronary artery bypass with bilateral internal thoracic arteries: Could smaller be considered better?}

\section{Daniel J. P. Burns, MD, MPhil}

The sternotomy remains the most common approach for most cardiac surgical procedures, allowing for excellent exposure, predictability, and a high degree of surgical control. When adopting a minimally invasive approach, a central principle is that the results achieved must be, at minimum, the same as the conventional counterpart. If this can be achieved, then the minimally invasive approach can be considered better. However, it must also be recognized that as invasiveness decreases, complexity increases, and control over the procedure is necessarily diminished. In cardiac surgery, where there are multiple interactions necessary for the procedure, it is crucial to respect the balance between these factors. Minimally invasive cardiac surgery typically focuses on valve interventions. Although certain specialized centers have taken up minimally invasive coronary artery interventions enthusiastically, these complex and technically challenging procedures are less common than their valve counterparts.

When considering coronary artery bypass grafting (CABG), we continue to debate the merits of different

\footnotetext{
From the Department of Thoracic and Cardiovascular Surgery, Cleveland Clinic Foundation, Cleveland, Ohio.

Disclosures: Dr Burns is a consultant to Medtronic.

Received for publication Jan 4, 2020; revisions received Jan 4, 2020; accepted for publication Jan 5, 2020; available ahead of print Jan 31, 2020.

Address for reprints: Daniel J. P. Burns, MD, MPhil, Cleveland Clinic, 9500 Euclid Ave, J4-133, Cleveland, OH 44195 (E-mail: burnsd@ccf.org).

J Thorac Cardiovasc Surg 2021;162:1121-2

$0022-5223 / \$ 36.00$

Copyright (c) 2020 by The American Association for Thoracic Surgery

http://dx.doi.org/10.1016/j.jtcvs.2020.01.024
}

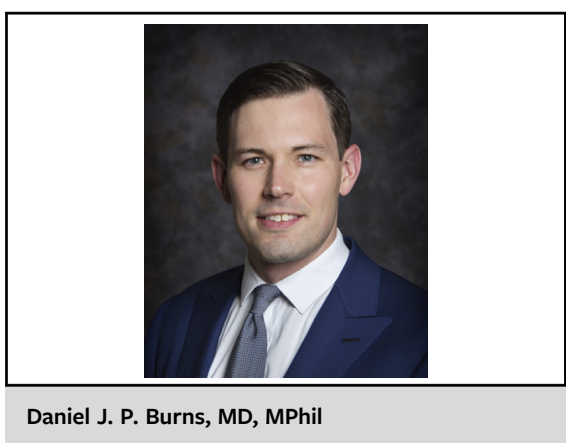

CENTRAL MESSAGE

Sternal-sparing minimally invasive coronary artery bypass using bilateral internal thoracic arteries can be performed safely with encouraging early patency results.

grafting strategies. It has been demonstrated that arterial grafts, when used correctly, can be expected to outlast saphenous vein grafts. ${ }^{1,2}$ Clinically, however, bilateral internal thoracic artery (BITA) use has shown inconsistent evidence. Although observational studies appear to support its use, a recent prominent trial demonstrated no mortality difference at 10 years. ${ }^{3,4}$ The question of BITA use in CABG should by no means be considered settled.

In this issue of the Journal, Davierwala and colleagues ${ }^{5}$ have endeavored to tackle both problems: minimally invasive multiarterial revascularization and use of bilateral internal thoracic arteries. ${ }^{5}$ Off-pump, minimally invasive, multivessel CABG via a left anterior thoracotomy was performed in 88 patients. BITA harvest was undertaken in a skeletonized fashion under direct vision. Y-grafting was used to avoid aortic manipulation. Overall results are encouraging. There was an absence of in- 